eikon ${ }_{\text {and culture }}^{\text {journal on semics }}$

Forms of

contemporaneity

in the news design

of the newspaper

O Estado de S. Paulo

This work examines news design in contemporary newspaper and has as its main purpose the investigation of sensitive and tangible aspects of its ways of presence, which are expanded and reconfigured under the influence of digitization of communications, connectivity and technological convergence. The proposed reflection is based on the materiality and relies on authors such as Hans Ulrich Gumbrecht, Marshall McLuhan and Vilém Flusser. From these theoretical foundations, the expressive manifestations of the contemporary Zeitgeist were sought in the design of the journal O Estado de S. Paulo. The appraisal of these forms emphasizes the coupling between aesthetic experience and communication.
$\mathrm{DO}$

10.20287/eikon-nO3-a13

Received / Recebido

28042018

Accepted / Aceite

18052018

Author / Autor

Solange Wajnman

Cristina Silva Ramos

Instituto de Comunicação e Design, Universidade Paulista Brasil

\section{Formas da}

contemporaneidade no design de notícias do jornal $O$ Estado de S. Paulo

Este trabalho examina o design de notícias d'O Estado de S. Paulo e tem como objetivo central a investigação dos aspectos sensíveis e corpóreos de seus modos de presença, os quais se ampliam e reconfiguram sob a influência da digitalização nas comunicações, da conectividade e da convergência tecnológica. A reflexão proposta tem como base as materialidades e se apoia em autores como Hans Ulrich Gumbrecht, Marshall McLuhan e Vilém Flusser. A partir desses fundamentos teóricos, buscaram-se as manifestações expressivas do Zeitgeist contemporâneo no design do jornal $O$ Estado de S. Paulo. A apreciação dessas formas enfatiza a acoplagem entre experiência estética e comunicação. 
Em A galáxia de Gutenberg, obra publicada em 1962, Marshall McLuhan, além de identificar a transformação cultural e antropológica promovida pela invenção da imprensa, anunciava que a maneira linear de pensar instaurada pela escrita já estava em vias de ser substituída por uma forma mais global de percepção e compreensão. Sem pretender demonstrar tal hipótese diretamente e nos limites deste trabalho, apenas perguntamos: dada a presença massiva atual das tecnologias conectadas e móveis, como se expressariam, grosso modo, algumas das qualidades de percepção e compreensão veiculadas pelo meio jornalístico? $\mathrm{O}$ atalho metodológico estaria, como desenvolveremos adiante, no estudo das formas do design de notícias ${ }^{1}$ de um dos mais importantes jornais do país: O Estado de $S$. Paulo, sob o ponto de vista do campo das materialidades ${ }^{2}$, com uma abordagem epistemológica próxima àquela de Mc Luhan.

Para chegar a esse questionamento, devemos lembrar que a trajetória de declínio do jornalismo impresso tem se evidenciado de muitas maneiras. A queda da circulação, do número de leitores, do tempo de leitura dos jornais, e, por decorrência, de sua rentabilidade como negócio são resultado do acirramento da concorrência de outros meios de informação mais ágeis e estimulantes. Estaria o jornal impresso, tal como o conhecemos, fadado ao desaparecimento? Tais dificuldades levantaram dúvidas para as empresas editoras sobre as possibilidades de reação a esse panorama.

É fato que os jornais já sobreviveram a desafios anteriores para o seu negócio e ambiente editorial, desafios estes muitas vezes impulsionados pela inovação tecnológica, do telégrafo à televisão. A capacidade de adaptação às novas circunstâncias sempre lhes forneceu uma estratégia de sobrevivência e é através da adaptação que estão reagindo a esse novo desafio. Esse processo acarreta mudanças consideráveis em vários aspectos de sua configuração e de seus conteúdos. Nesse contexto, a proposta do presente trabalho é, a partir do estudo das formas do design de notícias do jornal O Estado de S. Paulo ${ }^{3}$, compreender como essas mudanças refletem novas formas de percepção e sensibilidade.

O jornal entendido literalmente como "notícia impressa em papel" agora constitui uma parte relativamente modesta do mix que esse veículo se tornou, no qual as
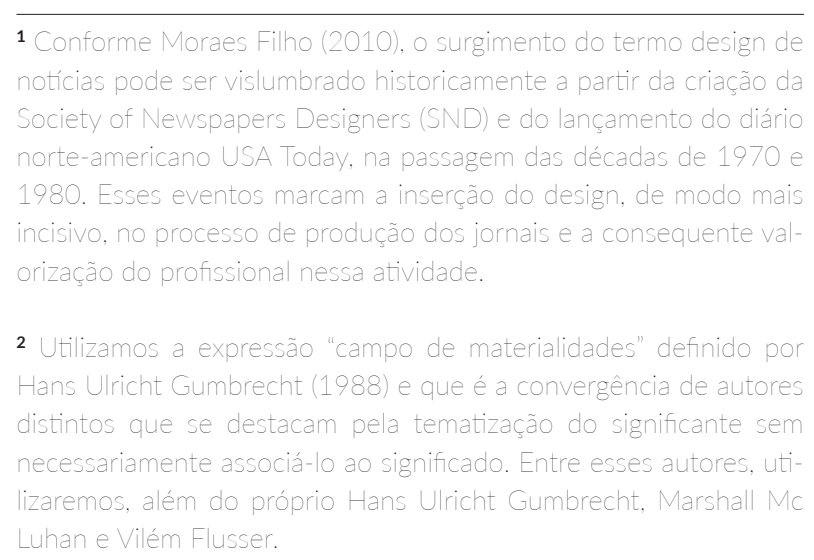
$3 \bigcirc$ Estado de São Paulo ou, conforme grafia de seu logotipo, 0
Estado de S. Paulo, também é conhecido como Estadão, ou Estado. notícias são relatadas em plataformas de mídia novas e múltiplas.

A atuação multiplataforma se apresenta como tendência irreversível para atender às demandas dos leitores, bem como às dos anunciantes. Porém, segundo revela o debate entre alguns gestores de importantes jornais ${ }^{4}$, a grande estratégia global extrapolaria a questão do digital. Segundo esse debate, tal estratégia se apoiaria na confiança de que conteúdo de qualidade, independentemente da plataforma de distribuição, é o que faz a diferença para preservar os jornais na posição de uma das instituições mais confiáveis.

Não obstante esse dado do debate sobre conteúdo de qualidade - circunstancial, todavia -, o que parece mesmo tomar vulto é a tendência do design como expressão material que cumpre diversas funções no panorama jornalístico: potencializar seu discurso; organizar grandes volumes de conteúdo em pacotes de informações relacionadas; trabalhar a tipografia para que seja confortavelmente legível e integrada às imagens; estruturar partes de páginas e seções para acomodar uma variedade de conteúdo baseado em texto ou em imagem; garantir, através de padronização, a agilidade na produção das edições diárias etc. Capaz de construir uma identidade única para o veículo, o design também é fundamental para reforçar uma marca institucional e comercial. Além disso, é capaz de agregar valor em qualquer produto, a princípio colaborando para a atratividade e a empatia imediata que posteriormente deverão evoluir para a afinidade, a identificação e a fidelização de seu público.

Nas interfaces digitais conectadas, essa importância ganha nova dimensão, pois os signos visuais devem atender ao objetivo consumatório da comunicação, bem como ao instrumental, uma vez que nesse ambiente interativo o usuário desempenha um papel determinante no ato de leitura que ali se constrói; ou seja, de seus "cliques" ou comportamentos influenciados pela mensagem propagada inicialmente depende o atendimento de suas necessidades ou a satisfação na consumação da mensagem posterior.

No mercado editorial jornalístico, esse contexto de mudanças resultou no desenvolvimento do que foi denominado design de notícias, como uma manifestação das mudanças estruturais na sociedade, sobretudo provocadas pelas novas tecnologias.

Nesse contexto, o objetivo desta investigação é examinar o design de notícias n'O Estado de S. Paulo do ponto de vista dos aspectos sensíveis e corpóreos dos seus modos de presença, os quais se ampliam e reconfiguram sob a influência da digitalização nas comunicações, da conectividade e da convergência tecnológica. Em outras palavras, vamos investigar como os aspectos sensíveis e corpóreos do jornal alteram a percepção de seu leitor em sua relação com o tempo, com o espaço, com as referências antigas, entre outras articulações. Trazemos neste artigo um extrato de um trabalho maior que pontuou as principais transformações do design do jornal da última década e que teve

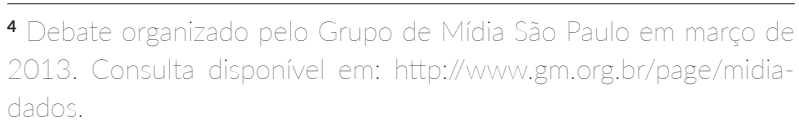


como recorte a cobertura jornalística das manifestações públicas de 2013 levando em conta os modos de articulação do design de notícias (fotos, desenho gráfica das matérias, modos de integração na página do jornal, movimento visual do todo) ${ }^{5}$.

Para trabalhar nessa proposta de investigação utilizamos a sistematização da Teoria das Materialidades de Hans UIrich Gumbrecht (1988), que propõe um raciocínio pautado no exame das configurações materiais do meio de comunicação. Trata-se, pois, "da possibilidade de tematizar o significante sem necessariamente associá-lo ao significado (1988, p. 145)". Ou, como observa o autor, trata-se antes de indagar "das condições de possibilidade de emergência das estruturas de sentido" do que identificar o sentido para logo resgatá-lo (Gumbrecht, 1988, p. 147).

Considera-se, sob esse ponto de vista, que as formas do design de notícias n'O Estado de S. Paulo ressaltam a relação entre experiência estética e experiência da comunicação, na medida em que as manifestações expressivas podem ser compreendidas além de mero suporte transmissor de um conteúdo, mas como uma atmosfera que envolve, estimula e modifica até fisicamente a relação com o leitor.

Propomos aqui a interconexão entre essas formas do design e a ambiência contemporânea discutida por Gumbrecht (1988) a partir dos seguintes conceitos: destemporalização, destotalização, desreferencialização, forma, acoplagem, simultaneidade e contingência. Voltaremos a esses conceitos mais adiante.

Atente-se que a reflexão proposta se apoia em Hans Ulrich Gumbrecht, mas também recebe a contribuição de outros autores que enriquecem esse campo da teoria das materialidades da Comunicação (designado pelo autor como não hermenêutico), como Marshall McLuhan e Vilém Flusser. Como primeira etapa de nossa investigação, ressaltamos um fio condutor que mostra as principais etapas da transição do design do jornal, desde o impresso até o digital. Como segundo movimento do texto, argumentamos sobre o vínculo entre o design de notícias, a cultura contemporânea e as bases do campo teórico das materialidades. Como terceiro e quarto movimentos, apresentamos com detalhes as unidades de análise ao mesmo tempo em que as cruzamos com os dados de observação empírica.

\section{A relevância do design no percurso do jornal}

Pode-se observar ao longo da última década uma sequência de mudanças sendo empreendida pelos principais jornais do país em diversos níveis: reformulação gráfica e editorial, incorporação de novas plataformas e estratégias de posicionamento no mercado. Atente-se também que, embora se valham praticamente dos mesmos elementos básicos de comunicação visual, o design mais recente, O Estado de S. Paulo, expressa relações entre linguagem verbal e não verbal baseadas nos discursos multimeios, enquanto o design das páginas de notícias até a década de 1990, portanto anterior à popularização da internet, expressava o predomínio da linguagem verbal. Observa-se o gradativo deslocamento do texto de sua posição predominante, na medida em que os recursos visuais, especialmente as imagens e cores, puderam realizar seu potencial comunicativo; movimento que conduziu à valorização do design.

5 AUTOR.ANO 2014
Também se observa como o design contribui para que o veículo lide com a concorrência de outras mídias, desde revistas ilustradas até a TV, e finalmente com a internet. Pode-se, nesse contexto, reconhecer o chamado "design de notícias", ou seja, aquele capaz de trabalhar como meio abrangente não restrito somente à página impressa, mas aquele envolvido nos processos decisórios da produção e na construção do discurso jornalístico.

Em março de 2000, o grupo Estado lança oficialmente o portal Estadão, reunindo todo conteúdo produzido pelos jornais O Estado de S. Paulo e Jornal da Tarde, pela Agência Estado, pela Rádio Eldorado e pelas listas O Estadão. Seguindo a tendência dos portais, o projeto adotou também uma gama de serviços variados que na página principal se apresentavam em uma navegação secundária posicionada na vertical esquerda, destacados por um módulo em um tom de azul mais forte, no qual também se acomodava a ferramenta de busca pelo site. Os números demonstravam que naquele momento a internet já pode ser definitivamente encarada como um meio de comunicação de massa cujo potencial afetava todos os setores da mídia - do rádio à televisão, da mídia impressa ao cinema. No Brasil, aproximadamente $4 \%$ da população tinha acesso à internet, ou seja, 6,79 milhões de pessoas conectadas, mas pesquisas previam que o número de internautas brasileiros deveria chegar a 10 milhões até o final daquele ano (2000). O número de internautas crescia com o aumento da infraestrutura (como a expansão da rede de telefonia fixa), o maior uso do computador e a chegada de provedores gratuitos. Além do entretenimento, a internet já se estabelecia na vida cotidiana através dos serviços públicos (como entrega de declarações de imposto de Renda), bancários e no comércio.

De fato, podemos dizer que somente em 2004 o jornal faz uma reforma mais eficaz e traz um novo visual. Um aspecto importante na primeira etapa dessa reforma foi a definição da paleta de cores, que passou a ter papel importante no estabelecimento da identidade visual, atendendo à diversidade de novos cadernos, além dos tradicionais de política e economia (temas da semana, tecnologia etc., porém mantendo a consistência com a unidade do projeto geral. Em uma segunda fase, no final de 2005, foram repensadas a hierarquização, a tipografia e as regras de produção dos infográficos, além de criado outro caderno novo, o Paladar, enfocando a gastronomia.

Livre das restrições técnicas maiores, a mudança empreendida no redesign d'O Estado de S. Paulo, em 2004, foi mais conceitual, em função de uma nova visão do que seria o jornalismo do século XXI, com as pressões decorrentes da adaptação a um novo modo de leitura, do crescimento de oferta de suportes de informação e também do próprio ritmo de vida dos leitores.

Em 2007, paralelamente às inovações de sua edição impressa, o Estado reforça sua atuação na internet. O novo layout reflete a evolução tecnológica ocorrida no período, tanto na ampliação de sua largura para o mínimo de 800 pixels, o que permitiu um mais amplo e melhor planejamento da grade, quanto na utilização de cores e tipografia, com destaque para a opção de ajuste, pelo usuário, do tamanho da fonte para maior conforto de leitura.

A possibilidade técnica de melhor tratamento do design impacta consideravelmente na usabilidade. A nova barra de navegação, simulando abas, se ajustava no topo da página com o objetivo de facilitar a seleção e localização do leitor. 
Novas possibilidades de comunicação e interação oferecidas pela web foram incorporadas no portal. Notícias e comentários eram oferecidos ao leitor na forma de podcasts ${ }^{6}$, tornando-se "notícia portátil". A produção multimídia foi expandida e ganhou novas seções específicas.

Em 2008, a edição digital do jornal impresso disponibilizada no portal ganha uma visão mais moderna que utilizava o PDF ${ }^{7}$, a tecnologia paper que tornava possível a leitura do jornal como se o leitor estivesse folheando as páginas de edição impressa. No mesmo ano é lançada também a nova versão de seu WAP site. Com essa versão desenvolvida para celulares, o portal aumenta ainda mais sua abrangência de acesso móvel.

Finalmente, em 2010 inicia-se o re-design que implanta o projeto gráfico e de hipermídia que é o objeto da presente pesquisa. Trata-se de um momento de convergência.

Esse percurso aponta para a relevância do design, o qual, além de acompanhar e dar suporte às alterações editoriais, atua como um dos protagonistas das mudanças, representando a imagem e os valores específicos do campo jornalístico em um contexto de transformação. É nesse contexto que $O$ Estado de S. Paulo tem passado por contínuas alterações em seu projeto gráfico, além de progressiva ampliação em sua atuação em plataformas conectadas. Neste jornal, a aposta é que as duas plataformas são complementares, não concorrentes; portanto, papel e web devem estar cada vez mais conectados. Para tanto, são implantadas reformulações gráficas no impresso e no portal, além de reformulações nas seções e cadernos nos dois veículos. Também é lançada uma nova versão de seu aplicativo para celulares, bem como versões especificas para tablets, atendendo a uma tendência de leitura que se consolida (Figura 1).

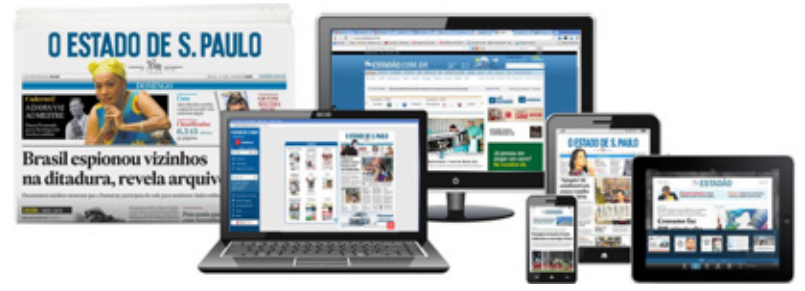

Figura 1

Com o redesign iniciado em 2010, o Estadão consolidou sua atuação multiplataforma.

\section{A transição do impresso para o digital n'O Estado de $S$. Paulo}

A transição da matéria para linguagem ou, no recorte de interesse deste trabalho, do impresso para o digital, introduz questões novas, tais como ergonomia cognitiva e visual, acessibilidade, usabilidade e interoperabilidade.

O primeiro momento da expansão da internet representou para os jornais a exigência de estar presente online, a princípio institucionalmente e depois, gradativamente,

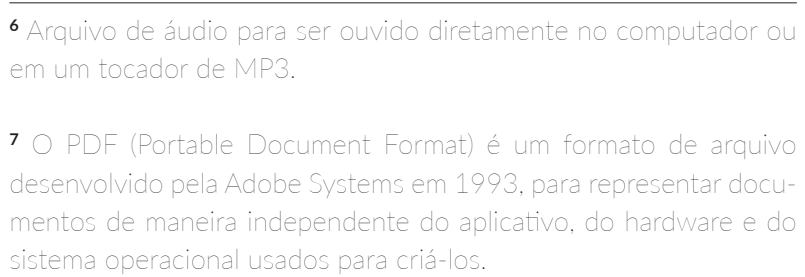

expandir essa presença aproveitando as possibilidades comunicativas que esse novo universo propicia, até tornarse um portal de notícias web.

Já no contexto da chamada Web $2.0^{8}$, as ferramentas de publicação acessíveis na rede revolucionaram o modo como as pessoas consomem, interpretam, produzem e divulgam informações. Assim, o papel que a internet assumiu na sociedade ganhou importância e a vasta interatividade proporcionou aos seus usuários/leitores assumirem protagonismo nesse cenário, com a chance de contribuir na rede através de comentários nas plataformas de notícias, nos fóruns de discussão, em blogs e nas redes sociais. Smartphones e tablets representam outra etapa para o jornalismo e seu design, por apresentarem uma versão concentrada, objetiva, talvez mais dramatizada e atraente da realidade. A informação disponível em modo textual, audiovisual ou digital precisa ser fornecida de acordo com necessidades espaciais ou temporais diferentes, em diversos formatos de tela, em variados dispositivos e plataformas operacionais.

Segundo pesquisa do Our Mobile Planet ${ }^{9}$ do Google, 59\% dos usuários brasileiros de smartphones acessam a internet no aparelho para "obter informações enquanto estiver longe do computador". Para esse público, o Estadão disponibiliza diversas versões.

O Estadão Móvel pode ser acessado por qualquer tipo de smartphone e o conceito de desenvolvimento responsive design faz com que a tela se adapte automaticamente a qualquer dispositivo. Essa versão traz o conteúdo geral do portal Estadão em forma reduzida e mais objetiva. Já o Estadão App traz notícias em tempo real. Ele apresenta possibilidades diversas de interação, compartilhamento e personalização de conteúdo conforme os principais interesses do usuário/leitor. Também disponibiliza acesso direto a serviços como cotações do mercado financeiro, previsão do tempo, acervo de imagens e a Rádio Estadão. Outros aplicativos específicos do Estadão são Economia \& Negócios, para acompanhamento do mercado financeiro; Divirta-se!, um guia interativo de cultura e entretenimento; e o Estadão Realidade Aumentada, para o conteúdo multiplataforma do Grupo Estado, como vídeos da TV Estadão e áudios da Rádio Estadão.

É fato também que os tablets inauguraram outro modo de acesso às notícias, ao permitir que o conteúdo, especialmente em vídeo e fotografia, seja consumido de forma confortável e individualizada, com facilidade de compartilhamento em vários níveis. Um dos maiores apelos dos tablets reside na interface touchscreen baseada em aplicativos, que é intuitiva e simples, e que qualquer pessoa, com qualquer idade, consegue manipular. Mas tais características de "amigabilidade" e "usabilidade" somente são

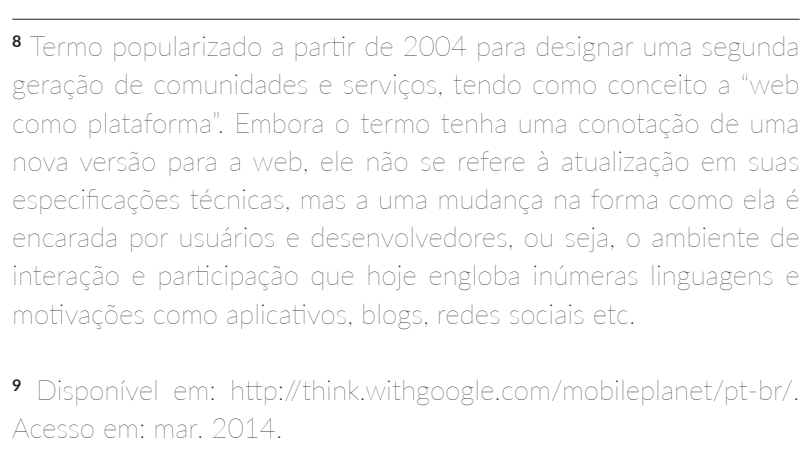


garantidas através do design eficiente, não apenas na "materialidade" dos aparelhos, mas principalmente das interfaces que neles se "materializam".

O Estadão tem diversos aplicativos para tablets. A versão Premium traz a íntegra da edição do jornal impresso com a vantagem da mobilidade, pois é possível baixar e ler todo o conteúdo offline. Seu layout reproduz exatamente o impresso e a interface inclui links para "saltar" até a página desejada e navegação no aplicativo. Já a versão light é mais compacta, trazendo somente as matérias principais da edição do dia. Seu design, porém, tanto no layout, diagramação e propostas de interação, apresenta maior aproveitamento dos potenciais e características do dispositivo, pois é possível assistir a vídeos, ter acesso a informações atualizadas e complementares, enviar mensagens ao jornal e aos colunistas, ver mais fotos etc.

O pacote de aplicativos para tablets do Estadão inclui ainda o Estadão Noite, uma edição vespertina publicada de segunda a sexta-feira, e o Estadão Fotos, publicado no sábado com as melhores imagens da semana.

Assim, nota-se que é cada vez mais necessário adaptar a linguagem em geral à comunicação móvel, correspondendo ao princípio de que é o cliente que decide o quê, quando e como recebe a informação. Não é mais suficiente importar conteúdos preparados para a imprensa escrita, digital, para o rádio ou televisão. As características, os recursos e as potencialidades do meio devem ser explorados para difundir, receber ou, ainda, permitir que seus usuários troquem informações entre si.

Se a desmaterialização através da digitalização é a etapa fundamental para a convergência, na qual assumidamente o Estadão tem apostado, os tablets configuram no momento atual o state-of-the-art para a viabilização de tal conceito. As propriedades e características desse dispositivo permitem mesclar os aspectos do impresso com as possibilidades hipermidiáticas da tecnologia eletrônica digital.

\section{Fenômenos contemporâneos maiores: fragmentação e desintegração}

Partimos da ideia de que o design corresponde ao "espírito do tempo" da contemporaneidade. De fato, como observa Faria, o design, enquanto um dos elementos da cultura, "[...] aponta e relaciona o seu entorno e caracteriza o cotidiano cultural de um grupo de indivíduos no tempo e no espaço" (Faria, 2008, p. 13). Caberia ao pesquisador apreciar a complexidade do momento presente, buscando entrelaçar os princípios filosóficos, ideológicos e conceituais com o design. Porém, antes de refletir sobre a relação entre contemporaneidade e design, é necessário perguntar: "O que é contemporâneo do quê?", conforme nos alerta Teixeira Coelho (1995). Na tentativa de resposta já é possível prever falha, pois se responderia "contemporâneo do meu presente", e esse presente já será passado no momento em que este texto for lido; já será história. É sabido que a história demanda um distanciamento para enquadrar fatos e fenômenos; portanto, na impossibilidade de tal distanciamento, recorre-se aqui, como referencial para a apresentação das noções de contemporaneidade, ao conceito de Zeitgeist ou espírito do tempo.

Tal analogia com o clima ou a atmosfera é explorada por Michel Maffesoli (2012), que utiliza a metáfora da "mudança climática" para chamar atenção ao imaginário que resumiria o espírito do tempo. "Cada um de nós é tribu- tário do clima no qual viveu. O clima nos determina, faz o que somos fisicamente. Da mesma forma, o imaginário é um clima que nos determina"10.

Assim, no interesse deste trabalho, permite-se um distanciamento de qualquer polêmica em relação ao entendimento dos conceitos de modernidade e pós-modernidade; enfatiza-se essa atmosfera do momento, que possa ser percebida sensivelmente como a visão de mundo predominante e suas manifestações.

O delineamento de fronteiras que possam distinguir modernidade e pós-modernidade suscita muitos debates, por vezes conflitantes. Em diversas áreas do conhecimento, como a comunicação, a sociologia e as artes, surgem estudos dedicados ao exame das principais linhas de pensamento do mundo ocidental nos últimos séculos. Entre essas disciplinas inclui-se o design, interessado

[...] não apenas na passagem do tempo ou na mudança de regras ocorridas na transição de uma era a outra. Mas também nas construções e reformulações as quais sofreu durante o processo. Transformações essas que foram profundas e que moldaram o próprio modo de fazer, perceber e consumir design (Amorim, 2006, p. 1).

A modernidade foi determinante para o design. No parecer de Teixeira Coelho (1995), a partir das tentativas de união entre arte e indústria, arte e máquina, e arte e técnica, em um processo longo e conflituoso de harmonização, a modernidade caracterizou um aspecto esteticista que foi um dos fatores decisivos para a conformação do design. Teixeira Coelho (1995) reflete também a respeito do ingresso das descobertas técnicas (eletricidade, automóvel, avião) no cotidiano da sociedade moderna como deflagradores de uma alteração radical no modo de vida.

Esse momento simbólico permite identificar, entre os pilares do mito moderno, a ciência e a tecnologia que geraram o funcionalismo, a mais perfeita tradução estética do Zeitgeist moderno. A beleza de um objeto "[...] já não seria incidental ou suplementar à sua função, porque a sua beleza seria agora a sua função" (Connor apud Amorim, 2006, p. 4). O funcionalismo seria, portanto, "[...] o marco da institucionalização dos cânones do design moderno, regidos pelos princípios de legibilidade, clareza, síntese e adequação à lógica da produção" (Amorim, 2006, p. 5).

Rick Poynor percebe, nos produtos da cultura pós-moderna, semelhanças com obras modernistas, mas observa que sua inspiração e propósito são fundamentalmente diferentes. "Se o modernismo buscava criar um mundo melhor, o pós-modernismo - para horror de muitos observadores - parece aceitar o mundo como ele é" (Poynor, 2010, p. 11). Segundo essa visão, o pós-modernismo se envolve em uma relação de cumplicidade com a cultura dominante, abandonando a aspiração de fazer distinções hierárquicas entre a valorizada "alta cultura" e a "baixa cultura", como ocorria no modernismo. Essa atitude resulta em liberdade expressiva, permitindo que "novas formas híbridas floresçam" (Poynor, 2010, p. 11).

A ausência de regras e padrões autoritários cria condições mais flexíveis de produção, ao menos na esfera cultural. Características como "[...] fragmentação, impureza da forma, ausência de profundidade, indeterminação, intertextualidade, pluralismo, ecletismo e um retorno ao vernacu-

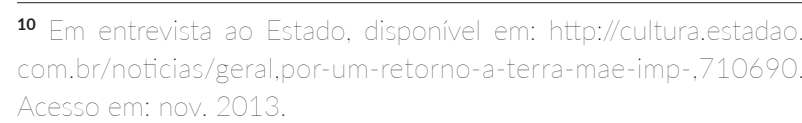


lar" (Poynor, 2010, p. 12) ficam presentes sem pudores. Para Hans Ulrich Gumbrecht, a versão filosoficamente mais interessante do conceito de pós-modernidade consiste em entendê-la como situação que desfaz, neutraliza e transforma os efeitos acumulados das modernidades ${ }^{11}$. Nessa compreensão, a pós-modernidade problematiza a subjetividade, e o campo hermenêutico, o tempo histórico e, sob certo ângulo, a crise da representação.

Gumbrecht identifica como significativa a impressão de que "[...] o ritmo da mudança, após atingir velocidades inauditas durante o século XIX e a primeira metade do século XX, chegou agora a uma desaceleração" (Gumbrecht, 1998b, p. 21).

No entanto, há que se entender que isso não significa que os acontecimentos e mudanças relevantes tenham se processado em menor número; significa somente que "[...] estamos nos afastando do cronótopo do 'tempo histórico', com seus imperativos implícitos de mudança e inovação" (Gumbrecht, 1998b, p. 22).

Nesse contexto, diminui o anseio por um futuro que parece negativamente predeterminado pelas consequências indesejáveis do passado. Por outro lado, perde-se a ambição de superar ou distanciar-se do passado, uma vez que ele está sempre presente através das técnicas de preservação e reprodução.

McLuhan já comentava que a imprensa "[...] forneceu uma memória enorme e nova para os escritos do passado, tornando a memória pessoal inadequada" (McLuhan, 2006, p. 199), e acrescentava que "[...] a data é o único princípio organizativo da imagem jornalística da comunidade. Eli-mine-se a data, e o jornal de um dia se torna igual ao do dia seguinte. Ler um jornal de uma semana atrás sem perceber que não é de hoje é uma experiência desconcertante" (McLuhan, 2006, p. 240).

Recorda-se aqui a capacidade de memória fornecida pelo computador. No contexto da tecnologia e das redes, a data representa apenas uma chave primária de pesquisa dentro da memória jornalística que se estende através dos dados armazenados nas informações acessíveis via internet.

Ao observar o objeto deste estudo, o jornal O Estado de S. Paulo em suas múltiplas plataformas, encontra-se um exemplo desse fato na seção Acervo do portal Estadão, o qual disponibiliza na internet a íntegra do acervo de mais de 2,4 mi-lhões de páginas publicadas desde 1875. Assinalamos que ele atualmente se constitui em uma plataforma de mídias diversas, sendo os smartphones e tablets uma nova etapa na consagração desses universos conectados.

McLuhan já antecipava tal sensação de desintegração quando dizia "[...] a aceleração da velocidade da forma mecânica para a forma elétrica instantânea faz reverter a explosão em implosão" (McLuhan, 2006, p. 53). A mesma relação pode ser entendida quando ele se referia à fra-gmentação: "A reestruturação da associação e do trabalho humanos foi moldada pela técnica de fragmentação, que constitui a essência tecnológica da máquina" (McLuhan, 2006, p. 53).

Disso se depreende que os novos meios eletrônicos implodem os demais meios, levando-os também à fragmentação. Esses "velhos" meios, como o jornal, precisam então se re- inventar, buscando, por um lado, sua "arte" (como sugere McLuhan) e, por outro, a adaptação às circunstâncias geradas pela internet. Assim, abraçam a convergência, que pode reprocessar as mensagens que eram do jornal, do rádio e da TV, resultando em um jornalismo que pode ter características mais participativas.

É dessa maneira que argumentamos que o design do jornal se adapta às características pós-modernas. Em sua materialidade, as formas de design refletiriam a ambiência de desintegração e fragmentação.

\section{Características da contemporaneidade e a materialidade das comunicações no design d'O Estado de S. Paulo}

\subsection{Dispositivo, forma e acoplagem}

Em consonância com a teoria das materialidades, partimos da ideia de que todos os princípios norteadores do design de notícias estão vinculados fundamentalmente ao suporte material necessário para o ato de comunicação se efetivar. No jornal impresso, esse espaço é o da página, e nos jornais online, os diversos aparelhos que estabelecem conexão com a web.

Portanto, a desmaterialização dos "objetos culturais" não implica que possam prescindir de um suporte físico. Sempre é exigida uma porção determinada do espaço, uma substância em determinada conformação de equipamento com volume e peso, que consome energia e que custa. Os apelos de consumo da tecnologia eletrônica digital sobre a sociedade contemporânea são evidentes e constantes provas disso.

Porém, além desse suporte material, a noção de dispositivo de imprensa abrange os aspectos tecnológicos dos mecanismos construídos para um determinado fim e também pode associar-se à ideia de estratégia, ou seja, "[...] à forma de disposição dos elementos constituintes de um engenho qualquer" (Freire, 2007, p. 39).

O dispositivo é uma maneira de pensar a articulação entre vários elementos que formam um conjunto estruturado, pela solidariedade combinatória que os liga. Esses elementos são de ordem material, mas localizados, agenciados, repartidos segundo uma rede conceitual mais ou menos complexa. O dispositivo constitui o ambiente, o quadro, o suporte físico da mensagem, mas não se trata de um simples vetor indiferente ao que veicula, ou de um meio de transportar qualquer mensagem sem que esta se ressinta das características do suporte. Todo dispositivo formata a mensagem e, com isso, contribui para the conferir um sentido (Charaudeau apud Freire, 2006, p. 76).

O raciocínio de Charaudeau, apresentado por Freire, conduz à compreensão do suporte como um elemento material do dispositivo de imprensa que funciona como canal de transmissão, mas que também envolve a noção do espaço que disponibiliza, das diversas formas de divisão e preenchimento desse espaço, e das condições de recepção de cada tipo de mídia.

Pensar o design diante dessa perspectiva transmídia também remete ao conceito de "forma", no âmbito da abordagem do campo não hermenêutico. Tal conceito se define a partir da proposta de Hjelmslev ${ }^{12}$ de que substância do conteúdo e 
substância da expressão dependem de uma "forma" para funcionar como operadores de sentido e que devem "acoplar-se" para se converterem em sentido articulado. No escopo deste trabalho, avalia-se que o pensamento sobre a "forma" envolve a noção de dispositivo de imprensa como um todo, que assim abrange os aspectos tecnológicos dos objetos, bem como as estratégias em relação à disposição dos elementos constituintes das interfaces das diferentes mídias.

Lembrando que as principais exigências instrumentais para a imprensa estão intimamente ligadas às questões do uso do espaço material, desenvolve-se a ideia do design de notícias como articulador do equilíbrio entre a qualidade do conteúdo, a facilidade de uso, a performance dos sistemas e, inclusive, os aspectos estéticos e simbólicos que proporcionam satisfação subjetiva através da sensação de bem-estar e identificação do leitor com o produto.

Tudo isso alude ao conceito de "acoplagem", conforme teorizado por Gumbrecht, que supõe a presença de dois sistemas em processo de interação. Assim, em um primeiro nível, tal acoplagem se localizaria tanto no contato do homem com os diferentes dispositivos de notícias quanto na inter-relação entre os sistemas que alimentam esses dispositivos. Como exemplo disso, no âmbito deste estudo de caso, pode-se associar a relação dos leitores tanto com o tradicional papel, como, no outro extremo, com as interfaces touchscreen dos tablets, intuitivas e de simples manipulação, ou com os smartphones tão indispensáveis que parecem efetivamente fazer parte dos sujeitos contemporâneos.

Lembra-se porém que, conforme Gumbrecht afirma:

A valorização do conceito de acoplagem relaciona-se com a pergunta sobre as condições de passagem da substância do conteúdo à forma do conteúdo. Esse conceito também ajuda a compreender a passagem da substância da expressão à forma da expressão. Explicando tal passagem, poderíamos entender como forma do conteúdo e forma da expressão se associam, engendrando o que denominamos de "representação" (Gumbrecht, 1998, p. 148-9).

Portanto, um segundo nível de acoplagem pode ser encontrado na nova lógica do jornalismo, onde o sentido se articula para o leitor através de pedaços da notícia coletados em diferentes canais dentro da proposta de convergência. Também nesse sentido de convergência, dessa feita cultural, pode-se refletir que uma característica bastante marcante é a presença de múltiplas vozes em vários formatos, atuando na composição do discurso jornalístico. No design, isso é representado por variações na composição, nos espaços dedicados aos depoimentos e aos comentários, em variações tipográficas que ressaltem tal diversidade, como veremos mais adiante.

As principais exigências instrumentais para a imprensa visibilidade, legibilidade e inteligibilidade - estão intimamente ligadas às questões do uso desse espaço material, o que pode validar a compreensão do design de notícias como um processo de projetação multidisciplinar, uma atividade profundamente modificada com as possibilidades ampliadas pelas novas tecnologias de comunicação e informação.

\section{Formas do design de notícias na contemporaneidade}

Neste item, vamos relacionar outras importantes unidades de análise indicadas por Gumbrecht com as formas do design d'O Estado de S. Paulo, tais como destemporaneidade, destotalização, desreferencialização, simultaneidade. Argumentaremos em seguida.

Sabe-se pela experiência cotidiana que o sujeito contemporâneo das grandes cidades vive cercado por uma enorme quantidade de representações visuais difundidas pelas mais diversas mídias.

Da mesma maneira, o atual modelo impresso do jornal $O$ Estado de S. Paulo é repleto de imagens, e seu portal na internet, além das imagens em cada matéria, apresenta seções específicas reunindo conteúdo em fotografia, vídeo e infográfico. Para os tablets, existe até mesmo uma versão de aplicativo especialmente dedicada às imagens da semana.

Todas essas representações parecem competir continuamente pela adesão desse sujeito contemporâneo, através das proposições de significação que elas veiculam. Ao imergir nessa experiência midiática e na relação social que elas propõem, o sujeito contemporâneo, em uma perspectiva de orientação, parece se desconectar da "vida real", bem como da convencional relação temporal em evolução linear do passado, para o presente e o futuro.

Recordando Flusser, o próprio contemplar uma única imagem já estabelece relações temporais transformadas, diferentes do padrão linear: "O vaguear do olhar é circular: tende a voltar para contemplar elementos já vistos. Assim, o 'antes' se torna 'depois', e o 'depois' se torna o 'antes'. O tempo projetado pelo olhar sobre a imagem é o eterno retorno" (Flusser, 1985, p. 7).

Portanto, pode-se refletir que as narrativas imagéticas observadas no jornal contemporâneo propõem uma construção não linear da significação que difere essencialmente do modelo anterior. Mas não somente as imagens parecem ter essa proposta; considere-se nesse escopo também a diagramação fragmentada, uma característica da retórica pós-moderna que condiz com a teoria de Flusser de que o "pensamento-em-superfície" estaria absorvendo o "pensamento-em-linha".

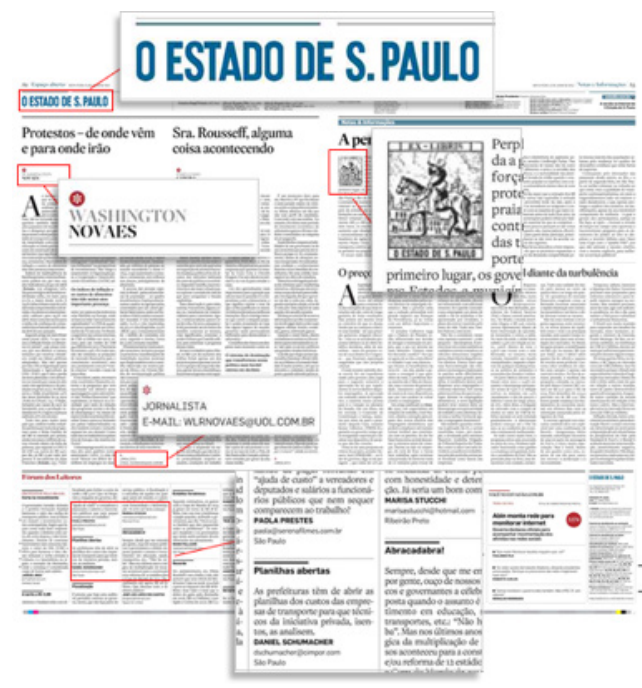

Figura 2

Páginas do jornal impresso demonstram como a narrativa imagética e a diagramação fragmentada contribuem para uma construção não linear da significação e convergem para o conceito de "destemporalização" de Gumbrecht. 
Tais considerações sobre a transformação da temporalidade linear dominante na cultura tipográfica convergem para o conceito de "destemporalização" proposto por Gumbrecht (1998). Na obra Corpo e forma, ele explica que no paradigma linear o tempo confunde-se com uma matéria que flui de um passado distinto do presente para um futuro em aberto, resultante das opções selecionadas no tal presente. Na situação contemporânea, por sua vez, as condições de "destemporalização" insinuam um tempo que não progride, um presente que se estende talvez ao "eterno retorno" citado por Flusser (1985).

Contribuem para tal sensação as possibilidades técnicas de reprodução do passado, "a tal ponto que, constantemente, o presente parece invadido por passados artificiais" (Gumbrecht, 1998, p. 138). Em consonância a esse pensamento, identifica-se o "revival" como uma das características da retórica visual pós-moderna, que propõe reviver visualidades tidas como ultrapassadas pelos modernistas.

No recente projeto gráfico do Estadão, pode-se perceber a presença de tal recurso a partir da reformulação e da valorização do antigo ex-libris.

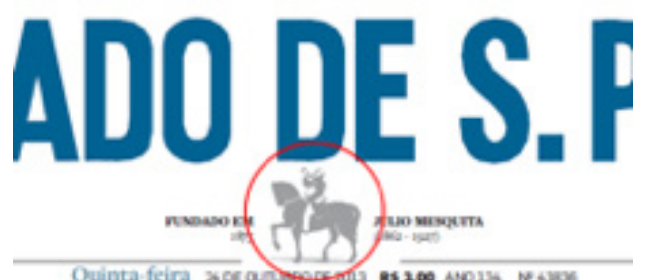

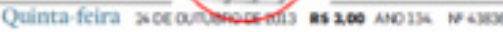

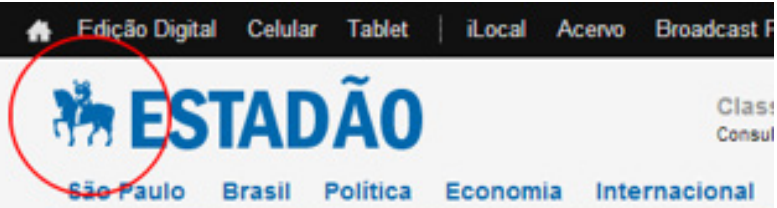

Figura 3

Exemplos da aplicação do ex-libris na capa e no editorial do jornal impresso, bem como no portal Estadão.

Esse símbolo é aplicado em sua forma clássica nos editoriais e, em sua forma renovada, em diversas situações na edição impressa e nas diferentes formas de veiculação digital. Resgatando esse elemento do passado, o veículo marca sua tradição e personalidade ao mesmo tempo em que atribui a tal símbolo o papel estratégico de elemento de vínculo na narrativa transmidiática composta pelas diversas plataformas em que ele se apresenta.

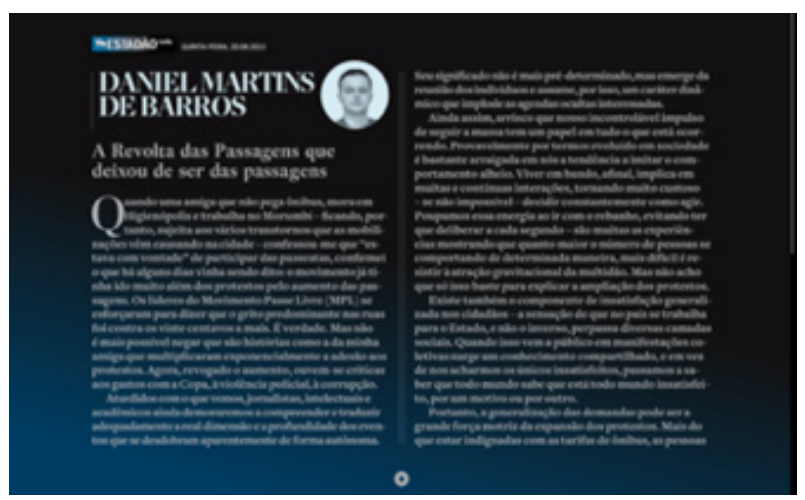

Figura 4

Tela de colunista no aplicativo Estadão Noite (Fonte: OESP).
Além disso, também se poderia incluir nessa característica de "revival" a formatação essencialmente clássica das colunas editoriais no aplicativo para tablets Estadão Noite, as quais, em uma interpretação pessoal, criam um estranho contraste com toda a aparência hightech do dispositivo eletrônico em si.

Outra forma de "invasão do passado" pode ser revelada no acesso ao acervo de edições anteriores digitalizadas através do portal Estadão, de modo que o passado está sempre disponível a um simples toque ou clique.

É assim que também se delineia também o outro conceito, aquele de "destotalização", definido por Gumbrecht a partir da verificação da impossibilidade de sustentar afirmações filosóficas ou conceituais de caráter universal. Como as mudanças no contexto sociocultural não param de acontecer, o sujeito pós-moderno seria mutante, inseguro, seguidamente se descobriria em contradição em relação a seus princípios e valores básicos. Frente a essa contingência, se desenvolveria um ceticismo progressivo na validade das abstrações absolutas.

Cauduro (2007) enfatiza que são traços típicos do pensar pós-moderno a "pluralidade de perspectivas, sentidos, métodos, valores; a procura e a apreciação de duplos sentidos e interpretações não consensuais, [...] desconfiança e atitude crítica em relação às grandes narrativas que se propõem a explicar tudo o que acontece no universo [...]" (Cauduro, 2007, p. 276).

Assim, parece que a meta do jornal contemporâneo não é a de poder explicar e controlar uma realidade, mas sim a de apresentar e apreciar, por múltiplos sentidos, diversas versões de realidade. No todo da cobertura impressa analisada são várias as remissões ao online, o qual, por sua vez, é rico em ofertas de conteúdo hipermidiático, apresentadas sob a forma de galerias de imagens, na Rádio e na TV Estadão, no acervo de edições passadas, nas apresentações digitais etc.

Tal variedade traz consigo a ideia da impossibilidade de se ter um sentido único para as coisas, e, ainda, a impossibilidade de um único meio de comunicação satisfatório. Portanto, fragmenta-se a informação, os meios, os modos e se inscreve a "simultaneidade" que Gumbrecht identifica com o "campo não hermenêutico". "O espaço teórico representado pelo campo não hermenêutico é constituído por relações de feedback, e tais relações definem-se enquanto simultâneas e não mais enquanto relações causais ou sequenciais" (Gumbrecht, 1998, p. 49).

Lipovetsky (2004) complementa Gumbrecht com a argumentação de que o período pós-moderno indica uma temporalidade marcada pelo imediatismo:

De um lado, a mídia eletrônica e informática possibilitam a informação e os intercâmbios em "tempo real", criando uma sensação de simultaneidade e de imediatez que desvaloriza sempre mais as formas de espera e lentidão. De outro lado, a ascendência crescente do mercado e do capitalismo financeiro pôs em xeque as visões estatais de longo prazo em favor do desempenho a curto prazo [...] as palavras-chave das organizações são flexibilidade, rentabilidade, just in time, "concorrência temporal", atraso zero - tantas orientações que são testemunho de uma modernização exacerbada que contrai o tempo em uma lógica urgentista (Lipovetsky, 2004, p. 62-3).

Essa característica se evidencia nas interfaces digitais através dos antetítulos que informam o horário de postagem das notícias, das chamadas para o blog Estadão Urgente, da faixa com contraste de cor que destaca as novi- 
dades relevantes sob o título "Agora no Estadão", da oferta constante de últimas notícias através do portal ou dos aplicativos para smartphones.

Percebe-se também no design do Estadão a intenção pontual de reproduzir ou mesmo de apropriar-se das referências da linguagem comum, atualmente muito associadas ao universo digital. Da edição impressa analisada recordase a reprodução de postagem online, o infográfico semeIhante aos aplicativos de mapas interativos, a diagramação de página dupla com traços de rede social, a simulação de um cursor etc.

Tais exemplos apontam para a subversão de um sistema de transmissão de referências que anteriormente vinham do topo da pirâmide cultural, para a atual prevalência das influências vindas de outras mídias ou da sociedade em geral, que tão rapidamente são disseminadas no universo hipermidiático. Recorda-se, a título de exemplo de diferença nessa lógica de referências, que na história do Estadão até mesmo a introdução da cor enfrentou resistência de conservadores que julgavam que ela não seria adequada à seriedade exigida de um veículo jornalístico.

Portanto, parecem características do contemporâneo a relação de cumplicidade com a cultura dominante; a falta de distinções hierárquicas entre a valorizada "alta cultura" e a "baixa cultura"; o acolhimento do vernacular expresso nas representações cotidianas, populares, elaboradas pelo sujeito comum.

Considerando a relação do jornal com a "desreferencialização" teorizada por Gumbrecht e ciente de que esta se refere à sensação de enfraquecimento de nosso contato com o mundo exterior, uma primeira reflexão conduz diretamente à transformação do hábito da leitura dos periódicos, antes tão associada ao modo de começar o dia. Provavelmente tal rotina cedeu lugar a um passar de olhos apressado pelas manchetes, à consulta das últimas notícias pelo smartphone e eventualmente à busca de alguma visão mais aprofundada sobre o assunto que mais se comenta nas redes sociais.

As palavras de Gumbrecht refletem bem essa situação ao afirmar que: "Em nossa práxis cotidiana, perdemos cada vez mais o contato direto, a fricção do corpo humano com o que se costumava denominar natureza, matéria. Perda que acarreta a sensação de enfraquecimento do contato com o mundo externo" (Gumbrecht, 1998a, p. 138). E complementa seu raciocínio: "Não me refiro ao que objetivamente constituiria este mundo, mas à impressão de que nos movemos num espaço pleno de representações que já não contam como referência segura de um mundo externo" (Gumbrecht, 1998a, p. 138).

Isso conduz à ponderação de que, por princípio, a referência ao mundo real seria fundamental no jornalismo. Parece tacitamente acordado que seu discurso, a exemplo da ciência, é aquele que poderia ser proferido, ouvido e aceito como verdadeiro ou autorizado. Rublescki (2009) considera que os leitores procuram nos jornais um sentido de ordem e de controle que se sobreponha à desordem do mundo; porém, citando Baudrillard, a autora pontua que na imprensa pós-moderna a verdade seria irrelevante, visto que, especialmente na mídia eletrônica e digital, a credibilidade das notícias estaria centrada na transmissão e não mais na apuração dos fatos.

Há muito tempo que a informação ultrapassou a barreira da verdade para evoluir no hiperespaço do nem verdadeiro nem falso, pois aí tudo repousa sobre a credibilidade instantânea. A informação é mais verdadeira que o verdadeiro, por ser verdadeira em tempo real - por isso é fundamentalmente incerta" (Baudrillard apud Rublescki, 2009, p. 5).

Portanto, se o imediatismo na divulgação dos fatos se mostra valorizado, justifica-se o discurso da convergência no qual se apoia o mais recente redesign do Estadão, que no jornal impresso fica aparente pelas diversas remissões ao online que já foram sinalizadas.

Por outro lado, as condições materiais do impresso não Ihe permitem atender à demanda pela informação em "tempo real"; assim, o jornal precisa se reinventar, buscar sua "arte", como sugere McLuhan (2006). Essa arte contemplaria atender à sua parte do acordo tácito e oferecer ao leitor o discurso verdadeiro e autorizado. Avalia-se que isso se manifeste editorialmente nos diversos apartes para "Análise" que podem ser observados na composição fragmentada dos layouts das páginas impressas.

"Opinião é, na pós-modernidade, o que bem condiz aos interesses comerciais das empresas jornalísticas e dos anunciantes", afirma Rublescki (2009, p. 6). Subordinado à lógica capitalista configurar-se-ia, então, um jornalismo voltado para o público, que em tempos do hiperespetáculo demanda imagem, interatividade, fragmentação. Nesse sentido, a profusão de imagens que por vezes determina a lógica da narrativa pode indicar uma crise de identidade para o jornalismo, onde perde a força seu bem até então mais precioso - o texto jornalístico. A estética da imagem cala o texto para seduzir o consumidor, mas também, de certa forma, para sustentar uma noção de verdade sob a perspectiva radical da contingência, ou seja, dinâmica e relativizada por tempo, espaço e ponto de vista.

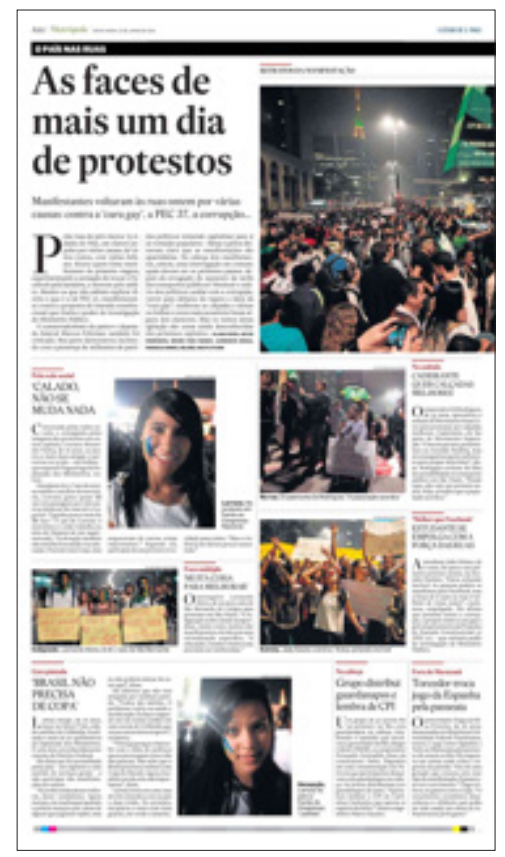

Figura 5

Detalhes mostram os diversos elementos que identificam as vozes atuantes e reduzem a impressão de um discurso monológico, destacando o papel dessas páginas como espaço de interações com leitores (Fonte: OESP).

Outro aspecto percebido refere-se à valorização dos espaços de opinião dos leitores. No Estadão impresso, tal aspecto se manifesta no "Fórum dos Leitores", na divulgação de resultados de enquetes online, na exposição de fotos e 
"perfis" de personagens das manifestações. No portal Estadão, isso é notado especialmente no espaço importante que ocupam os comentários reproduzidos das redes sociais. Circunstâncias de tal tipo possivelmente estejam associadas aos desejos de presença e intensidade relatados por Gumbrecht, os quais caracterizariam o "fim de uma cultura baseada na inconteste centralidade do medium linguagem e na representação como sua função inevitável" (Gumbrecht, 1998b, p. 27).

Conforme Gumbrecht, a assimilação do conceito de contingência traz, por um lado, uma imagem trágica do mundo, uma vez que já não se pode confiar no futuro. No entanto, a mesma noção de contingência desautoriza os sistemas políticos ou de pensamentos que pretenderam falar em nome do "sujeito transcendental".

Nesse sentido, percebe-se como oportuno o tema de coberturas jornalísticas selecionadas para esta análise - as manifestações públicas de junho de 2013. Nelas, o volume e a intensidade da mobilização da sociedade repercutiram mais que qualquer discurso formal seria capaz, trazendo à tona o tal sujeito citado por Gumbrecht (1998b), enfraquecido em consequência dos colapsos conceituais, mas sem perder sua complexidade e sua sofisticação como observador do mundo. A carência de uma ideologia ou discurso político que produza sentido e ordem acima das contingências foi tópico constante e inclusive documentado na cobertura analisada.

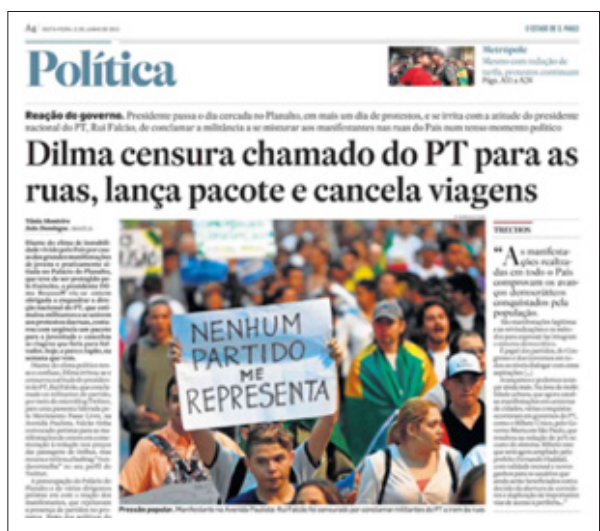

Figura 6

Na cobertura das manifestações, foi tópico constante o sentimento de ausência de representação política (Fonte: OESP).

Tal observação aponta para um aprofundamento possível a partir da teoria de Gumbrecht, no que esse autor define como "cultura de presença". Conforme Gumbrecht (2010), o contato humano com as coisas do mundo contém um componente de presença e um componente de sentido que a experiência estética permite experimentar. Ou, como se pode inferir com base nesta análise, a dimensão de presença predomina com base no "enriquecimento" que o design de notícias propicia ao discurso jornalístico através dos recursos gráficos e imagéticos, mas também através da narrativa transmídia que ora propõe.

\section{Considerações Finais}

O conceito de "aldeia global" na ocasião em que a obra de McLuhan foi escrita, meados dos anos 1960, parecia utópico demais, principalmente em um mundo dividido pela Guerra Fria. No entanto, no mundo digital contem- porâneo, as ideias desse autor sobre o futuro da comunicação ganham o status de profecias realizadas e se confirmam fundamentais para a compreensão de uma sociedade que constantemente se redefine por meio de suas tecnologias de comunicação.

Logo na introdução do livro Os meios de comunicação como extensões do homem, McLuhan comenta sua famosa frase "O meio é a mensagem", explicando que ela significa que, em termos da era eletrônica, já se criou um ambiente totalmente novo.

Essa noção de ambiente tem compreensão facilitada atualmente, quando, no contexto da internet, observa-se o surgimento de uma série de novos "ambientes digitais" que se tornaram corriqueiros na vida contemporânea, como as redes sociais, por exemplo. Da mesma forma quando se dá conta de como o telefone celular, ao fazer com que as pessoas possam ser encontradas em qualquer parte, embaçou os limites entre ambiente de trabalho e ambiente de lazer, percebe-se algo que transforma radicalmente a relação dos seres humanos com o espaço, bem como com o tempo.

Convivendo com esse fenômeno, é possível compreender esses ambientes conforme a concepção de McLuhan, como processos ativos e não simplesmente envoltórios passivos. "Contemplar, utilizar ou perceber uma extensão de nós mesmos sob forma tecnológica implica necessariamente adotá-la" (McLuhan, 2006, p. 64). Assim, a difusão de novas tecnologias de comunicação, tais como telefones celulares, computadores, tablets etc., com seu caráter instantâneo e conectividade ininterrupta, evidencia a noção de extensão de nossos sentidos, apresentada pelo teórico canadense.

Para ele, com o advento da tecnologia elétrica, o homem prolongou ou projetou para fora de si mesmo um modelo vivo do próprio sistema nervoso central. Talvez por isso o homem contemporâneo experimente a falta de seus gadgets com a ansiedade de uma amputação, com uma dor fantasmática muito mais vívida do que a falta de ferramentas poderia representar, mesmo que estas também possam ser entendidas como extensões humanas. $O$ fato desses aparelhos eletrônicos também apresentarem a capacidade de disponibilizar notícias pode intensificar essa relação de dependência, uma vez que potencialmente aliviariam a ansiedade de informação também típica desse homem contemporâneo, conforme Wurman (1991).

No mesmo livro anteriormente mencionado, McLuhan explica que o conteúdo de cada "novo ambiente" seria o "velho ambiente" reprocessado. Como exemplo, cita a TV que apresenta o "velho" cinema em um novo contexto de recepção e de formatação, em uma tela diferente, dividido em partes intercaladas por publicidade etc. Isso ajuda a perceber como a internet igualmente reprocessa a TV e as demais mídias com as quais interage, absorvendo e expandindo os elementos das velhas mídias.

Refletindo sobre a relação das novas tecnologias com a crise dos jornais impressos na contemporaneidade, ocorre a relação com o exposto por McLuhan sobre como a palavra escrita já sofrera com os efeitos dos meios elétricos (aos quais, além do rádio, TV e cinema, ele inclui o telefone):

[...] há também uma nova tecnologia elétrica que ameaça essa antiga tecnologia construída sobre o alfabeto fonético. Graças à sua ação de prolongar nosso sistema nervoso central, a tecnologia 
elétrica parece favorecer a palavra falada, inclusiva e participacional, e não a palavra escrita especializada. Nossos valores ocidentais, baseados na palavra escrita, têm sido consideravelmente afetados pelos meios elétricos, tais como o telefone, o rádio e a televisão. Talvez seja por isso que muitas pessoas altamente letradas encontrem dificuldade em analisar essa questão sem evitar um pânico moral (McLuhan, 2006, p. 100).

Acreditamos ter demonstrado como as formas do design encontram correspondência com as mudanças pelas quais a sociedade contemporânea tem se expressado da mesma maneira que McLuhan: pela tematização das formas materiais.

Assim, esse trabalho encontra conclusão coincidente ao demonstrar como a materialidade dos diversos modos de apresentação do jornal O Estado de S. Paulo condicionam a produção de sentido, e como o sentido emerge da acoplagem entre diferentes sistemas ou materialidades, ou, de modo mais complexo, na acoplagem de um sujeito e um objeto de comunicação. 


\section{Referências bibliográficas}

AMORIM, Patrícia. (2006). Dialogando com noções de modernidade e pós-modernidade: o design e o espírito do tempo. In: INTERCOM 2006 - XXIX Congresso Brasileiro de Ciências da Comunicação, 2006, Brasília.

CAUDURO, Flávio Vinicius. (2014). Pós-modernidade e hibridações visuais. Em Questão, Porto Alegre, v. 13, n. 2, p. 273-282, jul.-dez. 2007. Disponível em: http://revistaseletronicas.pucrs.br/ojs/index.php/revistafamecos/article/ view/480. Acesso em: 10 fev. 2014.

FARIA, José. N. (2008). Design, tecnologia e cultura contemporânea: do jornal impresso ao jornal em e-paper. 150 p. Dissertação (Mestrado em Design). Universidade Anhembi Morumbi, São Paulo - SP. Disponível em: http:// www.anhembi.br/ppgdesign/pdfs/joseneto.pdf. Acesso em: 12 jun. 2013.

FELINTO, Erick. (2001). Materialidades da Comunicação: por um Novo Lugar da Matéria na Teoria da Comunicação. Ciberlegenda (UFF), Niterói, n. 5.

FLUSSER, Vilém. (2010). A escrita. Há futuro para a escrita? São Paulo: Anna Blume.

(1983). Pós-história: vinte instantâneos e um modo de usar. São Paulo: Livraria Duas Cidades.

(1985). Filosofia da caixa preta. Ensaios para uma futura filosofia da fotografia. São Paulo: Hucitec.

(2007). O mundo codificado: por uma filosofia do design e da comunicação. São Paulo: Cosac \& Naify.

FREIRE, Eduardo Nunes. (2007). A influência do design jornalístico na evolução do discurso jornalístico. Um estudo de caso do jornal O Estado de S. Paulo. 187 p. Dissertação (Mestrado em Comunicação e Cultura Contemporâneas). Universidade Federal da Bahia, Salvador-BA: PPGCCC/ Facom/ UFBA. Disponível em: http://poscom. tempsite.ws/wp-content/uploads/2011/05/EduardoNunes-Freire.pdf. Acesso em: 12 abr. 2013.

GUMBRECHT, Hans Ulrich. (1998). Corpo e forma. Rio de Janeiro: Eduerj.

. (1998). Modernização dos sentidos. São Paulo: Ed.

34.

(1993). O Campo não hermenêutico ou a Materialidade da Comunicação. Rio de Janeiro: UERJ, Cadernos do Mestrado, n. 5.

(2010). Produção de presença: o que o sentido não consegue transmitir. Rio de Janeiro: Contraponto/Ed. PUC-Rio.

LEVY, Pierre. (1999). Cibercultura. São Paulo: Ed. 34.
MCLUHAN, Marshall; FIORE, Quentin. (2011). O meio é a mensagem: um inventário de efeitos. Rio de Janeiro: Ímã Editorial.

(2006). Os meios de comunicação como extensões do homem. Trad. Décio Pignatari. 18. ed. São Paulo: Cultrix.

MILL, John Stuart. (1831). The Spirit of the Age. The Collected Works of John Stuart Mill, Volume XXII Newspaper Writings December 1822 - July 1831. Disponível em: http://oll.libertyfund.org/option=com_ staticxt\&staticfile $=$ show . php $\% 3$ Ftitle $=256 \&$ chapter $=50$ 800\&layout=html\&ltemid=27\#a_813828. Acesso em: 29 set. 2013.

MORAES FILHO, Ary Pimenta. (2010). Design de noticias: um estudo de casos múltiplos. 194 p. Tese (Doutorado em Design) Pontifícia Universidade Católica do Rio de Janeiro, PUC-Rio, Brasil. Disponível em: http://www2. dbd.puc-rio.br/pergamum/biblioteca/php/mostrateses. php?open=1\&arqtese=0610642_10_Indice.html. Acesso em: 9 mar. 2013.

POYNOR, Richard. (2010). Abaixo as regras. Porto Alegre: Bookman.

RUBLESCKI, Anelise. (2009). Jornalismo pós-moderno: uma discussão dos valores míticos na sociedade hiper-espetacular. BOCC. Biblioteca Online de Ciências da Comunicação, v. 2009, p. 1-10. Disponível em: http://www.bocc. ubi.pt/pag/anelise-jornalismo-pos-moderno.pdf. Acesso em: 23 out. 2013.

SERRA, Paulo. (2006). O design na era da informação. Biblioteca Online de Ciências da Comunicação. Disponível em: http://bocc.ubi.pt/pag/serra-paulo-design-era-informacao.pdf. Acesso em: 28 jan. 2014.

TEIXEIRA COELHO, José. (1995). Moderno pós-moderno: modos \& versões. São Paulo: lluminuras.

LIPOVETSKY, Gilles. (2004). Os tempos hipermodernos.

São Paulo: Barcarola. 